\title{
Differences in the ability of apes and children to instruct others using gestures
}

\author{
Katja Grosse, ${ }^{1}$ Josep Call, ${ }^{1,2}$ Malinda Carpenter,,${ }^{1,2} \&$ Michael Tomasello ${ }^{1}$ \\ ${ }^{1}$ Department of Developmental and Comparative Psychology, Max Planck Institute for \\ Evolutionary Anthropology, Leipzig, Germany \\ ${ }^{2}$ School of Psychology and Neuroscience, University of St Andrews, St Andrews, UK
}

In press, Language Learning and Development

Acknowledgments: We thank Susanne Mauritz, Sandy Kennert, Susanna Jorek, Franziska Stock, Jennifer Hammann, Franziska Kröbel, Sandra Lipke, Gesa Volland, Katharina Kirchhofer, Ilmarie Määttänen, Steffi Gutknecht, and Frances Buttelmann for help with testing and reliability coding.

Address for correspondence:

Malinda Carpenter

Department of Developmental and Comparative Psychology

Max Planck Institute for Evolutionary Anthropology

Deutscher Platz 6

04103 Leipzig, Germany

carpenter@eva.mpg.de 


\begin{abstract}
In all human cultures, people gesture iconically. However, the evolutionary basis of iconic gestures is unknown. In this study, chimpanzees and bonobos, and 2-and 3-year-old children, learned how to operate two apparatuses to get rewards. Then at test only a human adult had access to the apparatuses and rewards. Children frequently produced appropriate iconic gestures but, with the exception of one human-raised chimpanzee, great apes did not gesture iconically. However, chimpanzees pointed to a reward outside the apparatus in another experimental condition, showing their motivation and ability to communicate with the human to request it. They also manipulated a duplicate apparatus in appropriate ways, though it was unclear if they did this to communicate with the human. Although great apes may have some of the prerequisite skills involved, iconic gestures come naturally to humans in a way that they do not for great apes.
\end{abstract}


Human communication is unique. Most obviously, only humans communicate using linguistic conventions that differ among different cultural groups. But, in addition, humans' natural gestures of pointing (and other deictic gestures) and pantomiming (and other iconic gestures) are human universals (Kita, 2003) and have been claimed to be species-unique modes of human communication (Tomasello, 2008).

The most basic of humans' natural gestures would seem to be pointing, which human infants typically begin doing before they have produced much, if any, conventional language (Carpenter, Nagell, \& Tomasello, 1998). Although great apes (henceforth apes) do not point for one another in their natural environments, apes in captivity do point for humans typically whole hand hanging in mesh caging in the direction of a desired object - to request/demand food (e.g., Leavens \& Hopkins, 1998; Leavens, Hopkins, \& Bard, 1996; Leavens, Hopkins, \& Thomas, 2004). They even point to tools that the human needs to have in order to fetch them food (Bullinger, Zimmermann, Kaminski, \& Tomasello, 2011; Call \& Tomasello, 1994; Zimmerman, Zemke, Call, \& Gómez, 2009).

But iconic gestures are another story. Iconic gestures are in many ways more similar to linguistic conventions than is pointing because even though they need not be conventional they are symbolic. (Following Piaget and many others, we refer to iconic gestures [as well as realistic drawings, sculptures, symbolic play, etc.] as 'symbols' and to the elements of a natural language and some conventionalized gestures as 'signs', which are symbolic by convention only.) For example, an airport security guard might twirl his finger in the air to indicate that the passenger should turn his body around, or one worker might gesture with a hammering motion to another worker across a construction site to request that a hammer be brought to him. The distinguishing feature of an iconic gesture is that through its resemblance to the intended referent it is meant to symbolize some action or object. Although it has not 
been studied nearly as much as pointing, several studies have found iconic gesturing in young children (e.g., McNeill, 1992; Nicoladis, Mayberry, \& Genesee, 1999; Özçalişkan \& GoldinMeadow, 2011; So, Demir \& Goldin-Meadow, 2010; Stefanini, Bello, Caselli, Iverson \& Volterra, 2009). However, little is known about young children's ability to create novel iconic gestures on the spot to instruct others about how to use a novel apparatus (see Behne, Carpenter, \& Tomasello, in press, for one recent study on this).

Tanner and Byrne (1996) have claimed that some captive gorillas sometimes use iconic gestures with one another (see also Savage-Rumbaugh, Wilkerson, \& Bakeman, 1977, for an example in bonobos). In contrast, Pika and colleagues found no iconic gestures in gorillas or bonobos (Pika, Liebal, \& Tomasello, 2003, 2005). One problem with an interpretation of the observed gestures based on iconicity is that almost all the reported examples involve one individual moving its arms in the direction in which she supposedly wants the other to move her body, and these could easily have different origins. That is, in the series of studies reviewed by Call and Tomasello (2007), one process by which great apes learn their gestures is posited to be ontogenetic ritualization. Applied to the gorilla examples, one could imagine that the first gorilla initially actually grabbed the second gorilla and attempted to move her body in the desired direction. Then, across repeated instances of this, once the second gorilla came to recognize what the first was attempting to do, she went ahead and moved in that direction as soon as the first gorilla began to initiate her attempt. This led the first gorilla to abbreviate her attempt into a shortened act (not a symbolic representation of an act or an object, as in iconic gestures). Although this ontogenetic ritualization explanation also fits other data on gorilla gestural development (e.g., Gómez, 1990) and what we know about other aspects of great ape cognition and communication, the fact is that at this point we do not know which interpretation of these observations of gorilla gestures is the correct one. 
The aim of this study was to directly compare children and apes in the same task by investigating the use of iconic gestures experimentally. We tested 2- and 3-year-old children because studies using natural observations of children in their homes show that it is around this age that there is a spurt in children's production of iconic gestures (e.g., Özçalişkan, Gentner, \& Goldin-Meadow, in press; Özçalişkan \& Goldin-Meadow, 2011). We tested chimpanzees and bonobos because they are humans' closest living primate relatives and they are capable of spontaneously developing pointing gestures and learning to communicate with humans using languages based on lexigrams or American sign language (Gardner, Gardner, \& Van Cantfort, 1989; Savage-Rumbaugh, 1986). We gave both children and apes the opportunity to use novel iconic gestures in highly motivating circumstances. After subjects learned how to operate two different apparatuses requiring different manipulations, the situation was that a human experimenter had access to one of the apparatuses but the subjects did not. In the key condition (Necessary), the apparatus had inside it a desirable reward, but the experimenter seemingly did not know how to extract it. Assuming that the experimenter would share the reward if she retrieved it, it was in the interest of the subjects to show her how to manipulate the apparatus so as to extract the reward with an iconic gesture. In another condition (Unnecessary) the reward was set in front of the apparatus so that all the subjects had to do was to direct the experimenter's attention to it in some way (e.g., by pointing), with iconic gestures being unnecessary. Based on previous studies, our prediction was that young children would gesture in both ways - iconically when that was needed, and deictically when that was needed. We also predicted that children would use iconic gestures much more often than apes, who might not use them at all (although the apes would be expected to point when the reward was in front of the apparatus). In addition, in order to give subjects another way to tell the experimenter how to manipulate the apparatus, in some trials subjects had available a 
duplicate of the apparatus which they themselves could potentially manipulate. This way we could test whether, if they did not gesture iconically, apes could still provide similar information to the experimenter with physical support.

\section{Study 1: Children}

\section{Method}

\section{Participants}

Sixteen children, 8 2.5-year-olds (mean age $=2 ; 7 ; 18$, range $=2 ; 6-2 ; 9$ ) and 83.5 -yearolds (mean age $=3 ; 7 ; 9$, range $=3 ; 6-3 ; 9)$ participated. Three additional children were tested but dropped from analyses for not participating in the second day of testing (one 2.5-year-old) and experimenter error (two 3.5-year-olds). There were equal numbers of boys and girls at each age. Participants were recruited from a database of parents who had volunteered to participate in child development studies.

\section{Materials and set-up}

All children were presented with two different apparatuses made out of transparent Plexiglas. Each held a marble and it was the child's task to get the marble out. One of the apparatuses was a tube which could be rotated to the left or right so that the marble inside would fall out (see Figure 1a). The other was a box which had to be pushed to one side so that the marble became reachable (see Figure 1b). Both apparatuses automatically resumed their initial position when no physical force was being applied. During the test phase, the experimenter and child were separated by a mesh screen, which prevented the child from reaching the apparatuses and the rewards during the test. 


\section{Figure 1}

\section{Design}

There were two experimental conditions: the unnecessary condition, in which the marble reward was easily available for the experimenter who was helping children at test (it was out in the open in front of the apparatus), and the necessary condition, in which the marble reward was inside the apparatus and the experimenter who was helping children seemingly did not know how to get it out of the apparatus. There was also a baseline period immediately prior to each of the tests, during which another experimenter (the 'baiter', see below) was present but ignoring children and thus not available to help children get the reward.

Children were tested on two days within one week, with two sessions per day (with a 10-minute break between sessions). All children participated in both experimental conditions with each of the two apparatuses, for a total of 16 trials (two trials on each apparatus in each of four sessions). The order of conditions and apparatuses was counterbalanced, with the two trials on each apparatus blocked, and the order of the presented apparatuses switched on the second day. In the second and third sessions a duplicate of each apparatus was fixed on children's side of the mesh, to give them the opportunity to demonstrate directly on the apparatus how the helper could obtain the marble, in case they did not gesture iconically. For these two sessions, the side that these apparatuses were on was counterbalanced within and across sessions. 


\section{Procedure}

After warming up with both experimenters (the 'baiter' and the 'helper') in a waiting room, children accompanied the experimenters to a testing room, where they were introduced to a chute that made a musical sound when marbles were dropped into it. The marbles rolled into a closed box children could not open, so they could not get them out again (this was done to keep children motivated to obtain further marbles). After placing two marbles into the chute, the helper told children she had an earache, and the baiter suggested that she wear headphones. The purpose of the headphones was to reduce verbal communication by children with the helper. To demonstrate that the helper could not hear with the headphones on, the baiter attempted several times unsuccessfully to speak with her loudly, finally getting her attention only by tapping her on the shoulder.

The helper, with the headphones on, went behind a large opaque screen (so she could not see how the apparatuses worked) while the baiter introduced each apparatus in turn (tube first) to children. The baiter pointed out that there was a marble inside, and children were allowed to try to get it out, with verbal - but never gestural - help from the baiter if needed. Before moving on to the test phase, children successfully had to get three marbles out of each apparatus consecutively and put them into the chute. At this point, the apparatuses were on the floor in front of the mesh screen from the child's perspective.

Then the baiter put the apparatuses away briefly and children received three helping trials, designed to show children that the helper was willing to help them. For each of these three trials, the baiter moved to the other side of the mesh screen from children and placed a marble on a small piece of cloth (to keep it from rolling) on the table. She then said that she needed to write something down and busied herself at this, ignoring children for 30 seconds. 
Then the baiter left and the helper appeared and immediately gave the marble to children, regardless of children's previous or current behavior, to show them her willingness to give them the reward.

Then, for each test trial the baiter placed one of the apparatuses (which one was counterbalanced) on the experimenters' side of the table and put a marble either in front of the apparatus on the table (unnecessary condition) or inside the apparatus (necessary condition). For the baseline period she then busied herself writing for 30 seconds, ignoring children. This baseline period was designed to see how communicative participants' gestures were, that is, whether children would produce them even when there was no one on the receiving end. She left and the helper returned for the test. The helper, still wearing headphones, asked children, "What should I do now?", pretending not to see the marble. Her next actions depended on the condition and how children reacted. In the unnecessary condition, if children pointed to the marble she gave it to them after 30 seconds. If children did not point to the marble she waited for 30 seconds without giving the marble. In the necessary condition, if children pointed to the marble she demonstrated that she was unable to reach it, repeated "What should I do now?" (with a hands palm-up gesture to express her ignorance) and waited 60 seconds for children to gesture iconically, or to manipulate the corresponding duplicate apparatus on their side if it was present. If children did not act in any relevant way in this condition, after 10 seconds the helper began to try to manipulate the apparatus unsuccessfully. If children did not react at all, after a total of 30 seconds the helper left and went back behind the large screen. If children started acting (pointing, gesturing, or manipulating the duplicate apparatus), the helper stayed for a total of one minute.

In order to receive the marble in the necessary condition, when no duplicate apparatuses were available, children had to produce a clear iconic gesture. That is, for the tube 
apparatus they had to make a circular or semi-circular motion in a vertical plane, and for the box apparatus they had to move a body part (e.g., hand, finger(s), arm, head, leg) horizontally to either the left or the right side. When the duplicate apparatuses were available they had to either produce a clear iconic gesture or manipulate the corresponding apparatus in a correct and obvious way, that is, turn the tube more than $90^{\circ}$ or push the box out. If they did not receive the marble, the baiter took it out when she returned and did not give it to children.

After two trials with one apparatus (one trial in each condition), the baiter switched the apparatuses for two further trials with the second apparatus. Then they took a break (during which the baiter and child played with unrelated toys) while the duplicate apparatuses were either put up or taken down from children's side of the mesh. The second session of each day began with the three helping trials. On the second day, the entire procedure was repeated.

\section{Coding and analyses}

Videotapes of the response period (i.e., when the helper was inside) were used for the coding of three main behaviors: iconic gestures, apparatus manipulations, and pointing. Both iconic gestures and manipulations of the corresponding duplicate apparatus were coded following the same criteria the helper used to determine how to respond. Pointing was coded when children extended their finger(s) and/or hand(s) toward the marble and/or apparatus either in front of or through the mesh. If there was an interval of at least one second between different instances of a manipulation, iconic gesture, or point two separate behaviors were coded. The amount of time the experimenter (baiter or helper) stayed at the table was also recorded in order to calculate the rate (frequency per minute) of pointing, iconic gesturing, and apparatus manipulation.

To assess inter-rater reliability, a coder who was naïve to the hypotheses of the study 
coded $25 \%$ of the children at each age. Reliability was excellent (Spearman's rank correlation: average of time experimenter was present ( $\mathrm{sec}): r_{s}=0.913$; sum of points: $r_{s}=0.905 ;$ sum of apparatus manipulations: $r_{s}=0.947$; sum of turning tube: $r_{s}=0.939$; sum of pushing box: $r_{s}=0.851 ;$ sum of gestures: $r_{s}=0.895 ;$ sum of turning gestures: $r_{s}=0.908 ;$ sum of pushing gestures: $r_{s}=0.848, \mathrm{P}<0.0001$ in all cases).

We analyzed the three main dependent variables as a function of condition, type of apparatus, and age group. We analyzed whether individuals preferentially used those actions (either gestures or manipulations) that the experimenter needed to extract the reward from the apparatus. To be able to combine (and compare) the data from the two apparatuses, we considered turning the tube and pushing the box as appropriate actions when the corresponding duplicate apparatus at the experimenter's side was baited (e.g., pushing when the reward was in the box) and turning the tube and pushing the box as inappropriate actions when the other apparatus was baited at the experimenter's side. We used non-parametric statistics because the data failed to meet the normality assumption for parametric statistics.

\section{Results}

\section{Iconic gestures}

Overall, both 2- and 3-year-old children gestured iconically significantly more often when the reward was inside the helper's apparatus (necessary condition) than when it was outside the apparatus (unnecessary condition) (Wilcoxon test: 2 -year-olds: $\mathrm{T}=28, \mathrm{P}=0.016$, $\mathrm{N}=7(1$ tie); 3-year-olds: $\mathrm{T}=36, \mathrm{P}=0.008, \mathrm{~N}=8$ ). The 2 -year-olds produced 1.0 iconic gestures per minute, and the 3 -year-olds produced 1.63 iconic gestures per minute, in the necessary condition and almost none (0.02 iconic gestures per minute for both 2- and 3-year-olds) in the unnecessary condition. All children except one 2-year-old produced at least one iconic gesture 
in the necessary condition whereas only one 2-year-old and one 3-year-old produced one iconic gesture in the unnecessary condition. There were no significant differences in iconic gesture rate between age groups in either condition (Mann-Whitney test: necessary condition: $\mathrm{U}=24, \mathrm{P}=0.44, \mathrm{~N}=16$, unnecessary condition: $\mathrm{U}=31.5, \mathrm{P}=0.96, \mathrm{~N}=16$ ).

Since iconic gestures occurred almost exclusively in the necessary condition, the subsequent analysis focused on this condition only. Figure 2 presents the iconic gesture rate as a function of type of apparatus (tube/box), type of iconic gesture produced (turning/pushing), and age group. The 3-year-old children consistently produced iconic gestures that matched the action that was required to extract the reward. In particular, they preferentially displayed turning (as opposed to pushing) when the reward was in the tube (Wilcoxon test: $\mathrm{T}=36$, $\mathrm{P}=0.008, \mathrm{~N}=8$ ) and conversely, they preferentially displayed pushing (as opposed to turning) when the reward was in the box (Wilcoxon test: $\mathrm{T}=36, \mathrm{P}=0.008, \mathrm{~N}=8$ ).

The 2-year-old children showed the same pattern of results, but to a slightly weaker degree. Thus, although they also preferentially displayed turning when the reward was in the tube (Wilcoxon test: $\mathrm{T}=28, \mathrm{P}=0.016, \mathrm{~N}=7(1$ tie)) they only showed a trend to use pushing more often than turning when the reward was in the box (Wilcoxon test: $\mathrm{T}=25, \mathrm{P}=0.078$, $\mathrm{N}=7$ (1 tie)). Nevertheless, combining the data from both apparatuses revealed that, overall, both 2- and 3-year-old children produced a significantly higher rate of appropriate than inappropriate iconic gestures (Wilcoxon test: 2-year-olds: $\mathrm{T}=28, \mathrm{P}=0.016, \mathrm{~N}=7(1$ tie); 3-yearolds: $\mathrm{T}=36, \mathrm{P}=0.008, \mathrm{~N}=8$ ). The two age groups did not differ significantly in their rates of turning or pushing for either the tube (Mann-Whitney test: turning: $U=25, \mathrm{P}=0.51 \mathrm{~N}=16$, pushing: $\mathrm{U}=24, \mathrm{P}=0.44, \mathrm{~N}=16$ ) or the box (Mann-Whitney test: turning: $\mathrm{U}=29, \mathrm{P}=0.80, \mathrm{~N}=16$, pushing: $\mathrm{U}=16, \mathrm{P}=0.11, \mathrm{~N}=16)$. 
Figure 2

\section{Pointing}

Figure 3 presents the pointing rate as a function of condition, apparatus, and age. Overall, both 2- and 3-year-old children pointed at comparable rates in both conditions, that is, they each pointed roughly 2 to 2.5 times per minute in each condition (Wilcoxon test: 2 year-olds: $\mathrm{T}=24, \mathrm{P}=0.46, \mathrm{~N}=8 ; 3$-year-olds: $\mathrm{T}=23, \mathrm{P}=0.55, \mathrm{~N}=8$ ). However, 3-year-olds pointed more often in the unnecessary than the necessary condition with the tube apparatus (Wilcoxon test: $\mathrm{T}=35, \mathrm{P}=0.016, \mathrm{~N}=8$ ).

There were no significant differences in pointing rate between 2- and 3-year-old children in the necessary (Mann-Whitney test: $U=32, \mathrm{P}=1.00, \mathrm{~N}=16$ ) or the unnecessary condition (Mann-Whitney test: $\mathrm{U}=29, \mathrm{P}=0.80, \mathrm{~N}=16$ ).

Figure 3

\section{Apparatus manipulations}

Overall, both 2- and 3-year-old children manipulated the apparatuses at comparable rates in the necessary and unnecessary conditions (Wilcoxon test: 2 -year-olds: $\mathrm{T}=15, \mathrm{P}=0.94$, $\mathrm{N}=7$ (1 tie); 3-year-olds: $\mathrm{T}=12, \mathrm{P}=0.31, \mathrm{~N}=5$ (3 ties)). The 2 -year-olds manipulated the apparatus 2.0 times per minute in the necessary condition and 2.45 times per minute in the unnecessary condition. The 3-year-olds manipulated the apparatus 2.3 times per minute in the necessary condition and 2.35 times per minute in the unnecessary condition. There were no 
significant differences in manipulation rate between 2 - and 3-year-old children in either the necessary (Mann-Whitney test: $U=30.50, \mathrm{P}=0.88, \mathrm{~N}=16$ ) or the unnecessary condition (MannWhitney test: $\mathrm{U}=29, \mathrm{P}=0.80, \mathrm{~N}=16)$.

Figure 4 presents the manipulation rate as a function of condition, type of apparatus, type of manipulation (turning/pushing), and age. In the necessary condition (Figure 4a), neither 2-year-olds (Wilcoxon test: tube: $\mathrm{T}=15, \mathrm{P}=0.063, \mathrm{~N}=5$ (3 ties); box: $\mathrm{T}=10, \mathrm{P}=0.63$, $\mathrm{N}=5$ (3 ties)) nor 3-year-olds (Wilcoxon test: tube: $\mathrm{T}=10, \mathrm{P}=0.125, \mathrm{~N}=4$ (4 ties); box: $\mathrm{T}=14$, $\mathrm{P}=0.125, \mathrm{~N}=5$ (3 ties)) showed any significant differences in the use of turning vs. pushing for either apparatus. Combining the data from both apparatuses revealed that, overall, both 2- and 3-year-old children produced appropriate and inappropriate manipulations at an approximately equal rate (Wilcoxon test: 2 -year-olds: $\mathrm{T}=22, \mathrm{P}=0.22, \mathrm{~N}=7$ (1 tie); 3-year-olds: $\mathrm{T}=14, \mathrm{P}=0.125, \mathrm{~N}=5$ (3 ties)).

Similarly, in the unnecessary condition (Figure 4b) neither 2-year-olds (Wilcoxon test: tube: $\mathrm{T}=6, \mathrm{P}=0.88, \mathrm{~N}=4(4$ ties); box: $\mathrm{T}=15, \mathrm{P}=0.44, \mathrm{~N}=6$ (2 ties)) nor 3-year-olds (Wilcoxon test: tube: $\mathrm{T}=3.5, \mathrm{P}=0.75, \mathrm{~N}=3$ (5 ties); box: $\mathrm{T}=8.5, \mathrm{P}=0.81, \mathrm{~N}=5$ (3 ties)) showed any significant differences in the use of turning vs. pushing for either apparatus. Combining the data from both apparatuses revealed that, overall, both 2- and 3-year-old children produced appropriate and inappropriate manipulations at an approximately equal rate (Wilcoxon test: 2year-olds: $\mathrm{T}=17, \mathrm{P}=0.22, \mathrm{~N}=6$ (2 ties); 3 -year-olds: $\mathrm{T}=8, \mathrm{P}=1.0, \mathrm{~N}=5$ (3 ties)).

Figure 4

Neither age group showed a significant preference for using apparatus manipulations over iconic gestures in the necessary condition (Wilcoxon test: 2 -year-olds: $\mathrm{T}=22, \mathrm{P}=0.56$, 
$\mathrm{N}=8$; 3-year-olds: $\mathrm{T}=18, \mathrm{P}=1.0, \mathrm{~N}=8$ ). Additionally, we found no conclusive evidence of a trade-off between apparatus manipulations and iconic gestures when the two age groups were analyzed separately (Spearman test: 2-year-olds: $r=-0.26, \mathrm{P}=0.53, \mathrm{~N}=8 ; 3$-year-olds: $\mathrm{r}=-0.49$, $\mathrm{P}=0.22, \mathrm{~N}=8$ ). However, when we analyzed both groups together, we found that the higher the rate of iconic gestures, the lower the rate of apparatus manipulations (Spearman $\mathrm{r}=-0.51$, $\mathrm{P}=0.04, \mathrm{~N}=16)$.

\section{Discussion}

In line with our hypotheses, children used appropriate iconic gestures (i.e., turning when the reward was in the tube and pushing when the reward was in the box) in the necessary condition. This was especially true of 3-year-olds, but also, to a slightly lesser degree, of 2-year-olds. In contrast, children hardly ever used iconic gestures in the unnecessary condition, in which they were not needed. Instead, children of both ages quite often pointed in the unnecessary condition (children often pointed in the necessary condition as well, and this was to be expected because pointing provided some information in that condition too, i.e., about the fact that a marble was in the apparatus). In short, children of both ages pointed when that might be effective, but also used iconic gestures appropriately when they were needed.

Although the pattern of apparatus manipulations in the necessary condition (unlike that in the unnecessary condition) mirrored that of the iconic gestures, children did not use appropriate apparatus manipulations at a significant level (i.e., turning the tube and pushing the box when the reward was in the tube and box, respectively), partly because about half of the children displayed the same rates for turning and pushing for each apparatus. Thus, children manipulated the apparatus but they did not seem to use it to show the adult what to do. One reason for this might be that children find iconic gestures natural for symbolization, 
but they find it difficult to use objects as symbols due to what DeLoache (2004) has called the dual representation problem. In her studies using replicas and scale models, DeLoache finds that it is mostly not until children are 3 years of age or older that they really can understand one object (which has its own properties as a physical object) as symbolizing another. A second possibility is that as children get older they are less flexible in using communicative means other than those they normally use (see Namy \& Waxman, 1998, for evidence for this effect in the way that young children use either gestures or words to designate objects). However, note that we found no preference for iconic gestures over apparatus manipulations in either of the age groups and a trade-off between iconic gestures and apparatus manipulations when all children were pooled together. Although iconic gestures may have carried the weight of the communicative exchanges with the experimenter, it is conceivable that the role of apparatus manipulations was not completely negligible as a communicative device. Future studies should further investigate this issue.

\section{Study 2: Apes}

Method

\section{Participants}

Nine chimpanzees (Pan troglodytes) and four bonobos (Pan paniscus) of various ages participated (see Table 1). An additional bonobo female was tested but was not included in the analyses due to lack of participation. Both species were socially housed in enclosures in the Wolfgang Köhler Primate Research Center with both outdoor and indoor areas that were equipped with climbing structures and natural vegetation. They were fed four times a day on a diet of fruit, vegetables, and chow, and water was available ad libitum. All apes were motherreared except Limbuko and Kuno, who were nursery-reared by humans, and Alex, who had 
been human-reared and trained until he was 3 years, 3 months of age together with two other chimpanzees (not included in the current study) before he was integrated into a social group composed of six individuals. All apes were used to selecting between alternatives (e.g., a choice between a baited and an empty cup) by touch or by proximally pointing to them. Moreover, all apes except Luiza, Gertruida, Fifi, and Jahaga had been involved in studies that tested the production and comprehension of pointing to objects (Bullinger et al., 2011; Tomasello \& Carpenter, 2005; Zimmermann et al., 2009).

\section{Materials and set-up}

The apparatuses (Figure 1) and set-up were very similar to those used in Study 1 (except that of course the mesh was made of metal). Instead of marbles, grapes were used as rewards.

\section{Design}

Apes participated in the same experimental conditions (unnecessary, necessary) and the baseline period but they received more trials than children. Apes were tested on four days within two weeks, with one session per day. In each of the four sessions they received eight test trials, four with each apparatus, two in the unnecessary and two in the necessary condition, in alternating order, for a total of 32 trials. As with children, in the second and third sessions a duplicate of each apparatus was fixed on the apes' side of the mesh.

\section{Procedure}

Like children, apes began by learning how the apparatuses worked. Both apparatuses 
were attached to the mesh in their enclosure and apes were allowed to manipulate them to figure out how to get the grape out. Before going on to the test phase, apes had to obtain the grape successfully 35 times from each apparatus over the course of 3 days. By the end of these trials, all apes had figured out how to open the apparatuses relatively quickly, within approximately 5 seconds.

At the beginning of each session there were 3 helping trials, to show apes that the helper was willing to help them. For each of these trials, the baiter placed a grape on the table and then, unlike with children, left the room. After 60 seconds, the helper came in, gave apes the grape through the mesh, and left again.

The baiter then put a grape either in front of the apparatus on the table (unnecessary condition) or inside the apparatus (necessary condition), and left the room for the baseline period, which lasted 60 seconds. The helper then returned for the test. The helper behaved in exactly the same way as with children except that the response periods lasted longer than with children. That is, in the unnecessary condition, if apes pointed to the grape the helper gave it to them after 60 seconds. If apes did not point to the grape, the helper waited for 60 seconds without giving the grape. In the necessary condition, if apes pointed to the grape the helper demonstrated that she was unable to reach it and waited 2 minutes for apes to gesture iconically, or to manipulate the corresponding duplicate apparatus on their side if it was present. If apes did not act in any relevant way in this condition, after 30 seconds the helper began to try to manipulate the apparatus unsuccessfully. If apes did not react at all, after a total of 60 seconds the helper left the room. If apes started acting (pointing, gesturing, or manipulating the duplicate apparatus), the helper stayed for a total of two minutes. 


\section{Coding and analyses}

Coding was done as with children. To assess inter-rater reliability, a coder who was naïve to the hypotheses of the study coded $30 \%$ of the chimpanzees and $25 \%$ of the bonobos. Reliability was excellent (Spearman's rank correlation: average of time experimenter was present $(\mathrm{sec}): r_{s}=0.913 ;$ sum of points: $r_{s}=0.93 ;$ sum of apparatus manipulations: $r_{s}=0.977$; sum of turning tube: $r_{s}=0.947$; sum of pushing box: $r_{s}=0.881, \mathrm{P}<0.0001$ in all cases, $\mathrm{N}=128$ ). The correlation for sum of gestures, turning gestures, and pushing gestures could not be calculated because subjects did not gesture - and both coders agreed in $100 \%$ of the trials.

Data were analyzed in the same way as with children except that we did not analyze the performance of bonobos separately because the small sample size $(\mathrm{N}=4)$ made the interpretation of the tests meaningless. In this study we also compared apes' performance in the experimental period to their performance in the baseline period (we did not do this comparison for children in Study 1 because having the baiter stay in the room was not an ideal situation for a baseline period; it was done only for practical reasons so as not to leave children alone in the room). This comparison informs us about how communicative apes' gestures were in the experimental conditions, although it should be noted that the baseline period was not a counterbalanced condition but always came first.

\section{Results}

\section{Iconic gestures}

Twelve of the 13 apes failed to use any iconic gestures at any time during the experiment. The one exception was the human-raised and trained chimpanzee, Alex. In the necessary condition only, and mostly with the tube apparatus (2.1 times per minute with the tube apparatus and 0.1 times per minute with the box apparatus), Alex cocked his head in a 
kind of turning motion. Of course this is not demonstrating exactly what the human should do

- the human should use her hands to turn the apparatus (as Alex himself had done in manipulating his apparatus) - but still the head movement did create a turning, rotational motion. To test the hypothesis that Alex was simply making a motion relevant to what he would do if he had access to the apparatus, we looked at what he did in the baseline condition when he was alone in the room. He never once used this tilting head motion during the baseline period.

\section{Pointing}

Figure 5 presents the pointing rate as a function of condition, type of apparatus, and species. Overall, chimpanzees pointed at comparable rates in the unnecessary and necessary conditions (Wilcoxon test: $\mathrm{T}=33, \mathrm{P}=0.25, \mathrm{~N}=9$ ). However, their pointing rate was significantly higher in the experimental than the baseline period for both the unnecessary (Wilcoxon test: $\mathrm{T}=45, \mathrm{P}=0.004, \mathrm{~N}=9$; Median: Baseline=0.0; Experimental=2.44) and necessary conditions (Wilcoxon test: $\mathrm{T}=45, \mathrm{P}=0.004, \mathrm{~N}=9$; Median: Baseline=0.0; Experimental=2.24). There were no significant differences in pointing rate between chimpanzees and bonobos in the necessary condition (Mann-Whitney test: $\mathrm{U}=13, \mathrm{P}=0.50$, $\mathrm{N}=13$ ), but chimpanzees showed a lower pointing rate than bonobos in the unnecessary condition (Mann-Whitney test: $U=5, \mathrm{P}=0.05, \mathrm{~N}=13$ ). 
Iconic gestures 21

\section{Apparatus manipulations}

Overall, chimpanzees manipulated the apparatus in their enclosure at comparable rates in both conditions (Wilcoxon test: $\mathrm{T}=33, \mathrm{P}=0.25, \mathrm{~N}=9$ ). The chimpanzees manipulated the apparatus 2.52 times per minute in the necessary condition and 1.94 times per minute in the unnecessary condition. There were no significant differences in manipulation rate between chimpanzees and bonobos in the necessary condition (Mann-Whitney test: $U=10, \mathrm{P}=0.26$, $\mathrm{N}=13$ ), but chimpanzees showed a significantly higher manipulation rate than bonobos in the unnecessary condition (Mann-Whitney test: $U=3, \mathrm{P}=0.02, \mathrm{~N}=13$ ).

Figure 6 presents the manipulation rate as a function of condition, type of apparatus, type of manipulation (turning/pushing), and species. Focusing on the necessary condition (Figure 6a), chimpanzees used turning significantly more often than pushing with the tube apparatus (Wilcoxon test: $\mathrm{T}=41, \mathrm{P}=0.027, \mathrm{~N}=9$ ) but the reverse was not true for the box apparatus (Wilcoxon test: $\mathrm{T}=25, \mathrm{P}=0.82, \mathrm{~N}=9$ ). However, combining the data from both apparatuses revealed that, overall, chimpanzees produced more appropriate than inappropriate manipulations (Wilcoxon test: $\mathrm{T}=45, \mathrm{P}=0.004, \mathrm{~N}=9$ ).

In contrast, they did not produce more appropriate than inappropriate manipulations during the baseline period (Wilcoxon test: $\mathrm{T}=25, \mathrm{P}=0.82, \mathrm{~N}=9$ ). More importantly, a direct comparison between the percentage of appropriate actions used during the experimental and baseline periods revealed that chimpanzees produced a higher percentage of appropriate manipulations in the experimental than the baseline periods (Wilcoxon test: $\mathrm{T}=45, \mathrm{P}=0.004$, $\mathrm{N}=9$; Median: Baseline $=40.1 \%$; experimental $=70.5 \%$ ). 
In the unnecessary condition (Figure 6b), chimpanzees showed no significant differences in the use of turning vs. pushing for either apparatus (Wilcoxon tests: tube: $\mathrm{T}=38$, $\mathrm{P}=0.074, \mathrm{~N}=9$; box: $\mathrm{T}=33, \mathrm{P}=0.25, \mathrm{~N}=9$ ). Moreover, combining the data from both apparatuses did not change the results since, overall, chimpanzees did not produce significantly more appropriate than inappropriate manipulations (Wilcoxon test: $\mathrm{T}=38$, $\mathrm{P}=0.074, \mathrm{~N}=9$ ). Similarly, chimpanzees exhibited a comparable rate of appropriate and inappropriate manipulations during the baseline period for this condition (Wilcoxon test: $\mathrm{T}=19, \mathrm{P}=0.95, \mathrm{~N}=8)$.

Complicating matters, chimpanzees showed a trend toward more appropriate manipulations in the experimental than in the baseline period, even though the human did not need to manipulate the apparatus in the unnecessary condition (Wilcoxon test: $\mathrm{T}=39$, $\mathrm{P}=0.055, \mathrm{~N}=9$; Median: Baseline $=43.7 \%$; experimental=60.8\%). However, they produced more appropriate actions in the necessary than the unnecessary condition of the experimental period (Wilcoxon test: $\mathrm{T}=40, \mathrm{P}=0.039, \mathrm{~N}=9$ ), but the same was not true during the baseline period (Wilcoxon test: $\mathrm{T}=28, \mathrm{P}=0.57, \mathrm{~N}=9$ ).

Chimpanzees used turning significantly more often than bonobos in the unnecessary condition (Mann-Whitney test: $\mathrm{U}=5.5, \mathrm{P}=0.050, \mathrm{~N}=13$ ). There were no other significant differences between species in any other combination of variables (Mann-Whitney tests: $U>8$, $\mathrm{P}>0.19, \mathrm{~N}=13$ in all cases).

Table 2 summarizes the results of the two experiments. In general, both children and apes used pointing and apparatus manipulation but only children used iconic gestures. Most of the pointing gestures appeared when no specific instruction on how to manipulate the apparatus was needed (unnecessary condition). In contrast, apparatus manipulations, and especially iconic gestures, were more frequent when the experimenter needed instruction. If 
the analyses are restricted to appropriate apparatus manipulations and iconic gestures (rather than all apparatus manipulations and iconic gestures) the results remain largely unchanged.

Table 2

\section{Discussion}

With one possible exception, neither chimpanzees nor bonobos used any iconic gestures. The exception was the human-reared chimpanzee Alex, who repeatedly produced a kind of tilting head motion in the necessary condition, especially for the tube apparatus for which turning was appropriate, but he never produced this gesture when alone. As the human tilting her head in imitation of Alex would produce no relevant effects, if Alex intended his head motion to be communicative then it would have to symbolize the turning of the tube that would be effective. In contrast to the near absence of iconic gestures, many chimpanzees and bonobos pointed to the food for the human to show their desire for it. This shows that they were motivated for the food, and that they were capable of communicating with humans in order to get it. Something about iconic gestures, then, would seem to be especially difficult for great apes, perhaps because iconic gestures require a matching of specific actions between self and other, as in action imitation, which all apes find difficult (Buttelmann, Carpenter, Call, \& Tomasello, 2013; Tennie, Call, \& Tomasello, 2009).

Despite their lack of iconic gestures, chimpanzees produced more appropriate than inappropriate apparatus manipulations in the necessary condition, and did not do this in the unnecessary condition. They also produced more appropriate apparatus manipulations in the necessary than the unnecessary condition. The question is whether they were using these manipulations to communicate to the human what she should do, or, alternatively, whether 
they were simply (non-communicatively) performing on the duplicate apparatus the actions they would perform if they had the baited apparatus available to them. The baseline period becomes important here because if the chimpanzees were communicating to the human, then they should only perform apparatus manipulations when the human was present, or at least they should favor the production of appropriate over inappropriate apparatus manipulations only when the human was present (although recall that the baseline period was not a counterbalanced condition but always came first). Looking at the necessary condition, it was indeed the case that chimpanzees produced a higher percentage of appropriate actions when the experimenter was present than absent. However, they also tended to produce more appropriate than inappropriate actions when the experimenter was present rather than absent in the unnecessary condition. This is somehow problematic because the whole notion of appropriate and inappropriate is not really applicable here, since human apparatus manipulations would produce no relevant effects (the reward was outside the apparatus).

In sum, great apes pointed to the grape but they did not readily produce iconic gestures, and even Alex's head tilting was not a straightforward symbolizing of what the human should do. The apparatus manipulations, which possibly were produced communicatively, represent an intriguing finding to which we return in the general discussion.

\section{General Discussion}

In the current study the general finding was as hypothesized: the children fairly readily gestured for the helper both iconically and deictically, appropriate to the situation, whereas the apes (with one possible exception) only used pointing gestures and did not gesture iconically. The one possible exception in the use of iconic gestures was the only humanraised ape, the chimpanzee Alex, who tilted his head for the experimenter in the necessary 
condition for the tube apparatus - perhaps showing how the tube should go. Interestingly, Alex was raised by humans from birth, which may have influenced his communicative abilities with humans (Call \& Tomasello, 1996), but perhaps even more importantly, Alex had previously been extensively trained to imitate humans in a "Do As I Do" paradigm (Hribar, Sonesson, \& Call, 2014). This training does not translate directly to the current experimental situation, as the training involved Alex copying human actions, and in the current experiment there were no human actions to copy. Instead, Alex had to transform his previous learning - if that is what he did - by now, in essence, asking the human to imitate him. In any case, it is possible that Alex's training in matching actions with others led him to produce an action that, indirectly at least (his head symbolizing not the human's action but the tube's), was intended to communicate iconically.

Of course, it is possible that something else was going on, especially since Alex only did anything iconic for one of the two apparatuses. But, importantly, Alex did not tilt his head at all in the baseline period. A skeptic might argue that social facilitation could have been at work here: Alex was more aroused and so simply acted more when he was in the presence of others. However, this cannot be the full explanation because the specific action that increased (i.e., tilting the head like the tube should be tilted) was appropriate to the situation, and in addition in the two other situations in which the experimenter was present Alex did not behave in this manner: He rarely tilted his head in this way with the box apparatus and never did so in the unnecessary condition. In any case, regardless of whether this single action was an iconic gesture or not, the fact remains that none of the other apes produced these types of gestures, despite being clearly motivated to obtain the reward and perfectly capable of communicating with the human by other means - pointing - to request it.

Interestingly, chimpanzees produced more appropriate than inappropriate apparatus 
manipulations in the necessary condition when the experimenter was present. Additionally, they produced a higher percentage of appropriate apparatus manipulations when the experimenter was present rather than absent, especially when the experimenter needed those manipulations to retrieve the reward. Again the question is whether or not these apparatus manipulations were produced to communicate to the experimenter what she should do with the apparatus.

One possible interpretation of these results is that the apparatus manipulations were not communicative but instead simply reflected a differential activation of appropriate behaviors in the presence of the experimenter when the grape was inside the apparatus. It is unclear however, what the mechanism for such an activation would be. Another possibility is that the presence of the experimenter directing her actions at one of the apparatuses triggered in the chimpanzees some kind of motor anticipation for how one would manipulate the experimenter's apparatus in order to extract the food. Future studies should investigate these possibilities.

On the other hand, it could be that both children and chimpanzees were communicating with the experimenter to inform her about how to operate the apparatus, but they differed in their preferred means of communication: Whereas children used iconic gestures, chimpanzees used apparatus manipulations. If this were the case, it would have important implications for the evolution of human communication, particularly with regard to iconic gestures, because it would highlight both the similarities and differences between humans and one of our closest living primate relatives. That is, chimpanzees would be similar to humans in that they may share with humans the ability to request specific actions from others by enacting them, but different in that this ability is only expressed in the presence of a suitable physical support. 
We tried to code eye contact between apes and the experimenter as a way to determine apes' communicative intent. Although we witnessed some clear cases in which apes established eye contact while manipulating the apparatus, we were unable to code eye contact reliably due to non-ideal filming conditions. Another way to investigate whether apes' apparatus manipulations were communicative could be to use an apparatus amenable to gestural elaboration. Cartmill and Byrne (2007) have reported gestural elaboration by orangutans as a function of the level of comprehension of a recipient of those gestures. If one could find that apes tailor the type of apparatus manipulation they make to the observer's skill level, this would be strong support for a communicative account of these apparatus manipulations.

The importance of a physical support has been documented in several areas, including goal attribution and, again, imitation. With regard to goal attribution, Call, Hare, Carpenter, and Tomasello (2004) found that chimpanzees could more easily distinguish between an experimenter who was unwilling versus unable to give them a grape when the experimenter's behavior involved actions on the physical world. With regard to imitation, several studies in which apes have been trained to imitate on command have reported that actions that have a clearly specified physical end point (e.g., touching the top of the head with a hand) are easier for apes to imitate than those that lack a physical end point (e.g., raising a hand in the air) (Call, 2001; Custance, Whiten, \& Bard, 1995; Myowa-Yamakoshi \& Matsuzawa, 1999). Call (2001) has argued that the existence of a physical end point provides scaffolding for interpreting and copying those actions. In a similar way, the duplicate apparatus provided to apes in the current study could have scaffolded their communication, allowing them to communicate in a more concrete, less imaginary way than would be the case with iconic gestures. Again, raising parallels to imitation, it could be that the apparatus manipulations 
were analogous to emulation (i.e., showing how the object works) whereas iconic gestures would have been more analogous to imitation of actions (see Carpenter \& Call, 2009, for more on the tendency for apes to emulate rather than imitate).

Overall, then, the current results demonstrate very clearly that iconic gestures come naturally to human children in a way that they do not to the great apes. If we accept that the apparatus manipulations were truly communicative, it is possible that apes' lack of iconic gestures is related to their difficulties with action matching and imitation (e.g., Buttelmann et al., 2013), and not with an inability to communicate (request) precise courses of action from others in novel ways. But it is also possible that the apparatus manipulations were not truly communicative, and that great apes' problems with iconic gestures stemmed from an inability to comprehend that one may communicate with others by symbolizing (by whatever means) (see, e.g., Cartmill, Beilock, \& Goldin-Meadow, 2012; Tomasello, 2008). In either case, the facility of young children with iconic gestures is brought into sharp relief by documenting how difficult this form of communication is for our nearest primate relatives. But the possibility that apes can use other means of communication with proper scaffolding is an intriguing finding that should be followed up to determine more specifically what the apes were trying to do. 


\section{References}

Behne, T., Carpenter, M., \& Tomasello, M. (in press). Young children create iconic gestures to inform others. Developmental Psychology.

Bullinger, A., Zimmermann, F., Kaminski, J., \& Tomasello, M. (2011). Different social motives in the gestural communication of chimpanzees and human children. Developmental Science, 14, 58-68.

Buttelmann, D., Carpenter, M., Call, J., \& Tomasello, M. (2013). Chimpanzees, Pan troglodytes, recognize successful actions but fail to imitate them. Animal Behaviour, 86, $755-761$.

Call, J. (2001). Body imitation in an enculturated orangutan. Cybernetics and Systems, 32, 97-119.

Call, J., Hare, B., Carpenter, M., \& Tomasello, M. (2004). 'Unwilling' versus 'unable': Chimpanzees' understanding of human intentions. Developmental Science, 7, 488-498.

Call, J. \& Tomasello, M. (1994). Production and comprehension of referential pointing by orangutans (Pongo pygmaeus). Journal of Comparative Psychology, 108, 307-317.

Call, J. \& Tomasello, M. (1996). The effect of humans on the cognitive development of apes. In A.E. Russon, K.A. Bard \& S.T. Parker (Eds.). Reaching into thought (pp. 371-403). New York: Cambridge University Press.

Call, J. \& Tomasello, M. (2007). Comparing the gestural repertoire of apes. In J. Call \& M. Tomasello (Eds.). The gestural communication of apes and monkeys (pp. 197-220). Mahwah, NJ: Lawrence Erlbaum.

Carpenter, M. \& Call, J. (2009). Comparing the imitative skills of children and nonhuman apes. Revue de Primatologie [online], 1. http://primatologie.revues.org/263

Carpenter, M., Nagell, K., \& Tomasello, M. (1998). Social cognition, joint attention, and 
communicative competence from 9 to 15 months of age. Monographs of the Society for Research in Child Development, 63 (4, Serial No. 255).

Cartmill, E. A., Beilock, S., \& Goldin-Meadow, S. (2012). A word in the hand: Action, gesture, and mental representation in humans and non-human primates. Philosophical Transactions of the Royal Society, Series B, 367, 129-143.

Cartmill, E. A. \& Byrne, R. W. (2007). Orangutans modify their gestural signalling according to their audience's comprehension. Current Biology, 17, 1345-1348.

Custance, D.M., Whiten, A. \& Bard, K.A. (1995). Can young chimpanzees (Pan troglodytes) imitate arbitrary actions? Hayes and Hayes (1952) revisited. Behaviour, 132, 837-859.

DeLoache, J. (2004). Becoming symbol-minded. Trends in Cognitive Sciences, 8, 66-70.

Gardner, R.A., Gardner, B.T. \& Van Cantfort, T.E. (1989). Teaching sign language to chimpanzees. New York: SUNY.

Gómez, J.C. (1990). The emergence of intentional communication as a problem-solving strategy in the gorilla. In S.T. Parker \& K.R. Gibson (Eds.) "Language" and intelligence in monkeys and apes. Comparative developmental perspectives (pp. 333-355). New York: Cambridge University Press.

Hribar, A., Sonesson, G. \& Call, J. (2014). From sign to action. Studies in chimpanzee pictorial competence. Semiotica, 198, 205-240.

Kita, S. (Ed.). (2003). Pointing: Where language, culture, and cognition meet. Mahwah, NJ: Lawrence Erlbaum.

Leavens, D.A \& Hopkins, W.D. (1998). Intentional communication by chimpanzees: a crosssectional study of the use of referential gestures. Developmental Psychology, 34, 813822.

Leavens, D.A., Hopkins, W.D. \& Bard, K.A. (1996). Indexical and referential pointing in 
chimpanzees (Pan troglodytes). Journal of Comparative Psychology, 110, 346-353.

Leavens, D.A., Hopkins, W.D. \& Thomas, R.K. (2004). Referential communication by chimpanzees (Pan troglodytes). Journal of Comparative Psychology, 118, 48-57.

McNeill, D. (1992). Hand and mind: What gestures reveal about thought. Chicago: University of Chicago Press.

Myowa-Yamakoshi, M. \& Matsuzawa, T. (1999). Factors influencing imitation of manipulatory actions in chimpanzees (Pan troglodytes). Journal of Comparative Psychology, 113, 128-136.

Namy, L. \& Waxman, S. R. (1998). Words and gestures: Infants' interpretations of different forms of symbolic reference. Child Development, 69, 295-308.

Nicoladis, E., Mayberry, R. I., \& Genesee, F. (1999). Gesture and early bilingual development. Developmental Psychology, 35(2), 514-526.

Özçalişkan, Ş., Gentner, D., \& Goldin-Meadow, S. (in press). Do iconic gestures pave the way for children's early verbs? Applied Psycholinguistics.

Özçalişkan, Ş., \& Goldin-Meadow, S. (2011). Is there an iconic gesture spurt at 26 months? In G. Stam \& M. Ishino (Eds.), Integrating gestures: The interdisciplinary nature of gesture (pp. 163-174). Amsterdam, NL: John Benjamins.

Pika, S., Liebal, K. \& Tomasello, M. (2003). Gestural communication in young gorillas (Gorilla gorilla): Gestural repertoire, learning and use. American Journal of Primatology, 60, 95-111.

Pika, S., Liebal, K. \& Tomasello, M. (2005). Gestural communication in subadult bonobos (Pan paniscus): Gestural repertoire and use. American Journal of Primatology, 65, 3951.

Savage-Rumbaugh, E. S. (1986). Ape language: From conditioned response to symbol. New 
York: Columbia University Press.

Savage-Rumbaugh, E.S., Wilkerson, B.J. \& Bakeman, R. (1977). Spontaneous gestural communication among conspecifics in the pygmy chimpanzee (Pan paniscus). In G.H. Bourne (Ed). Progress in ape research (pp. 97-116). New York: Academic Press.

So, W. C., Demir, Ö. E., \& Goldin-Meadow, S. (2010). When speech is ambiguous, gesture steps in: Sensitivity to discourse-pragmatic principles in early childhood. Applied Psycholinguistics, 31(1), 209-224.

Stefanini, S., Bello, A., Caselli, M. C., Iverson, J. M., \& Volterra, V. (2009). Co-speech gestures in a naming task: Developmental data. Language and Cognitive Processes, 24, 168-189.

Tanner, J. E. \& Byrne, R.W. (1996). Representation of action through iconic gesture in a captive lowland gorilla. Current Anthropology, 37, 162-173.

Tennie, C.; Call, J. \& Tomasello, M. (2009). Ratcheting up the ratchet: On the evolution of cumulative culture. Philosophical Transactions of the Royal Society of London B: Biological Sciences, 364, 2405-2415.

Tomasello, M. (2008). The origins of human communication. MIT Press.

Tomasello, M., \& Carpenter, M. (2005). The emergence of social cognition in three young chimpanzees. Monographs of the Society for Research in Child Development, 70 (1, Serial No. 279).

Zimmermann, F., Zemke, F., Call, J. \& Gómez, J.C. (2009). Orangutans (Pongo pygmaeus) and bonobos (Pan paniscus) point to inform a human about the location of a tool. Animal Cognition, 12, 347-358. 
Table 1: Apes who participated in Study 2.

\begin{tabular}{|c|c|c|c|}
\hline Species & Name & Sex & Age at the time of testing \\
\hline \multirow[t]{4}{*}{ Bonobos } & Luiza & female & 6 \\
\hline & Yasa & female & 10 \\
\hline & Kuno & male & 11 \\
\hline & Limbuko & male & 12 \\
\hline \multirow[t]{9}{*}{ Chimpanzees } & Tai & female & 8 \\
\hline & Pia & female & 11 \\
\hline & Sandra & female & 17 \\
\hline & Gertruida & female & 17 \\
\hline & Fifi & female & 17 \\
\hline & Jahaga & female & 18 \\
\hline & Lome & male & 9 \\
\hline & Alex & male & 10 \\
\hline & Patrick & male & 13 \\
\hline
\end{tabular}


Iconic gestures 34

Table 2: Mean number \pm SEM (per min and trial) of gestures and apparatus manipulations in children and apes as a function of whether instructions to the experimenter were necessary or unnecessary.

Gestures

\begin{tabular}{|c|c|c|c|c|c|c|}
\hline & \multicolumn{2}{|c|}{ Iconic } & \multicolumn{2}{|c|}{ Pointing } & \multicolumn{2}{|c|}{ Apparatus Manipulation } \\
\hline & Necessary & Unnecessary & Necessary & Unnecessary & Necessary & Unnecessary \\
\hline
\end{tabular}

\section{Children}

$\begin{array}{lllllll}\text { 2-year-olds } & 1.0(0.2) & 0.0(0.0) & 2.0(0.4) & 2.4(0.5) & 1.3(0.4) & 1.3(0.5) \\ \text { 3-year-olds } & 1.6(0.4) & 0.0(0.0) & 2.3(0.4) & 2.4(0.5) & 1.7(0.6) & 1.1(0.5)\end{array}$

Apes

$\begin{array}{ccccccc}\text { Chimpanzees } & 0.1(0.1) & 0.0(0.0) & 2.8(0.8) & 3.2(0.8) & 2.9(0.4) & 2.4(0.4) \\ \text { Bonobos } & 0.0(0.0) & 0.0(0.0) & 3.7(1.5) & 7.4(1.9) & 1.8(0.5) & 0.8(0.1)\end{array}$


Figure 1. Different views of the apparatuses used with children and apes: a) the tube, b) the box.

a)
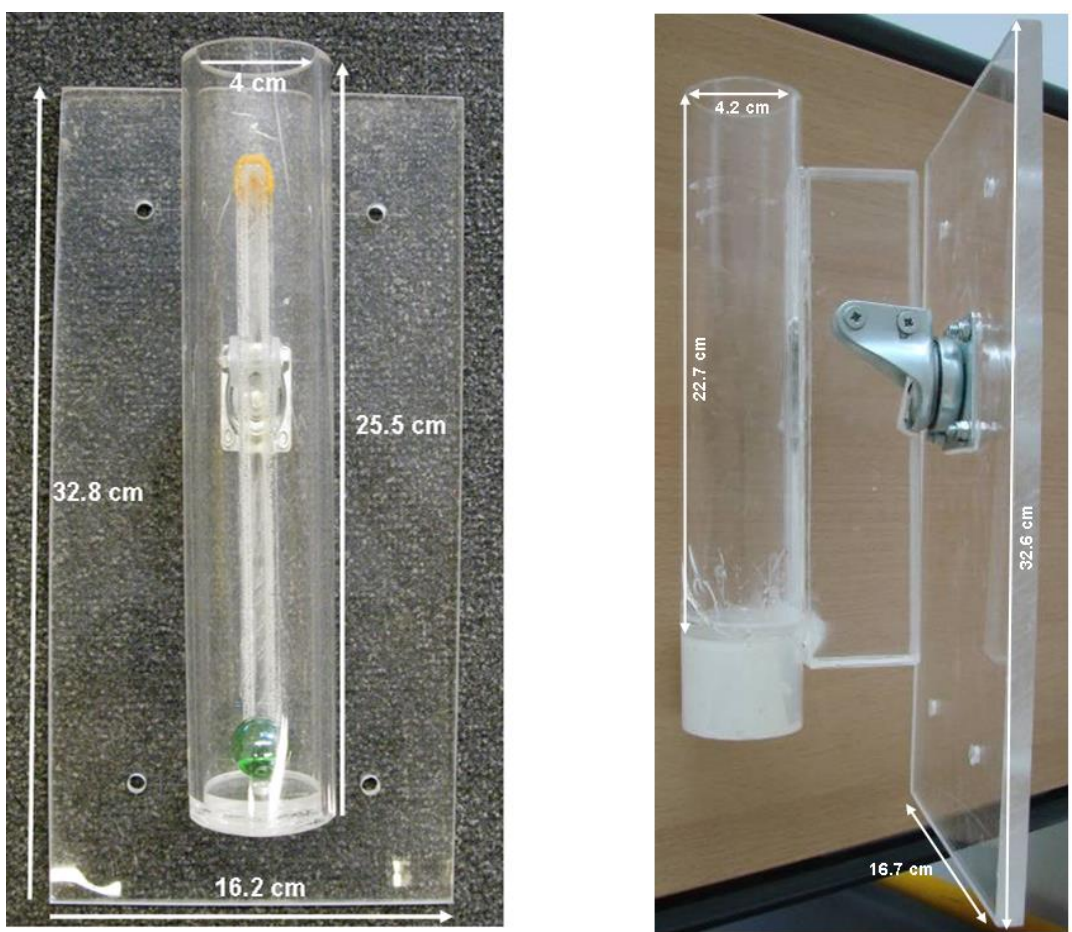

b)
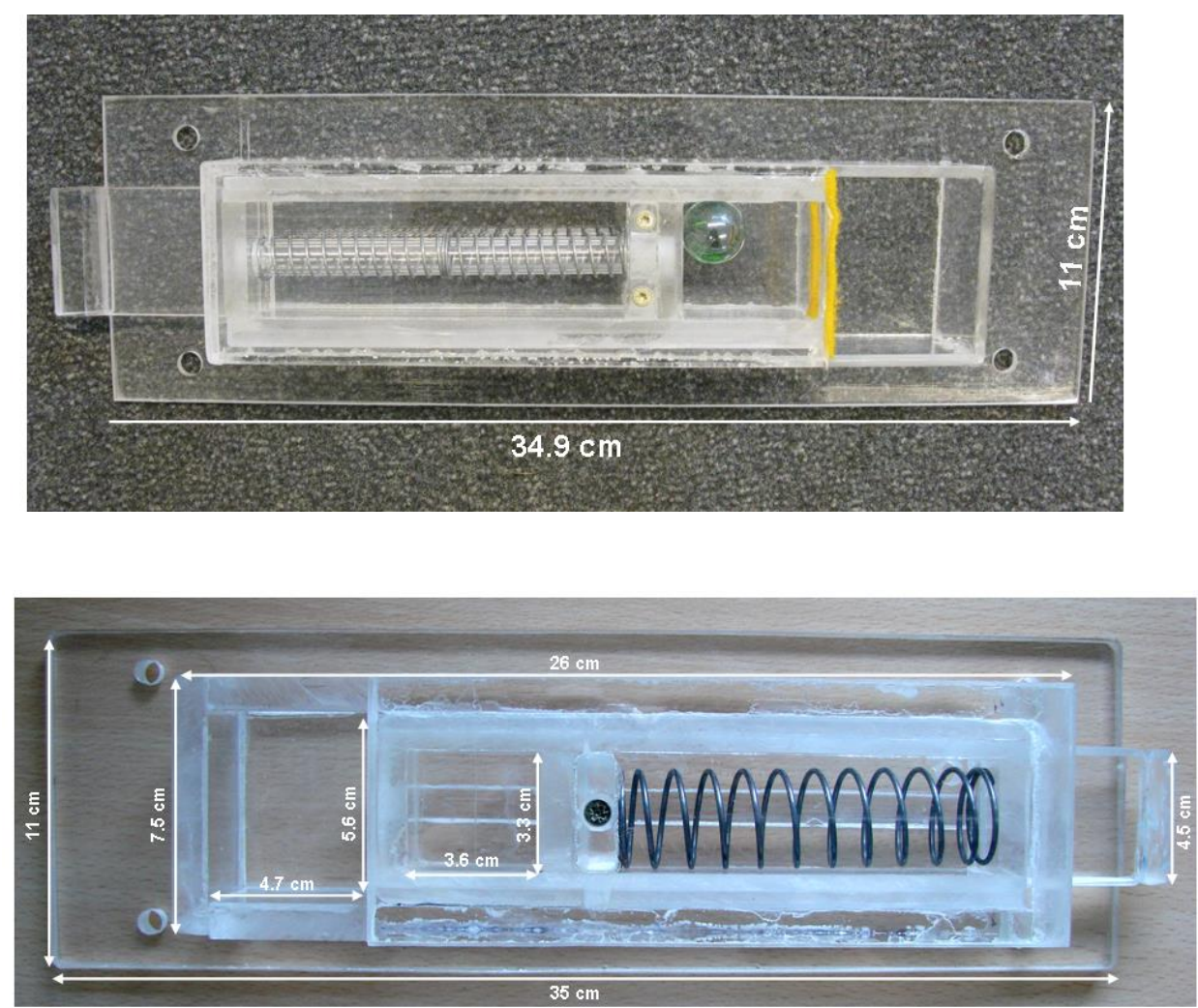
Figure 2. Mean (SEM) number of turning and pushing gestures per minute (and trial) as a function of apparatus type and age group in the necessary condition for children. Asterisks indicate a significant difference between conditions $(* p<0.05, * * p<0.01)$.

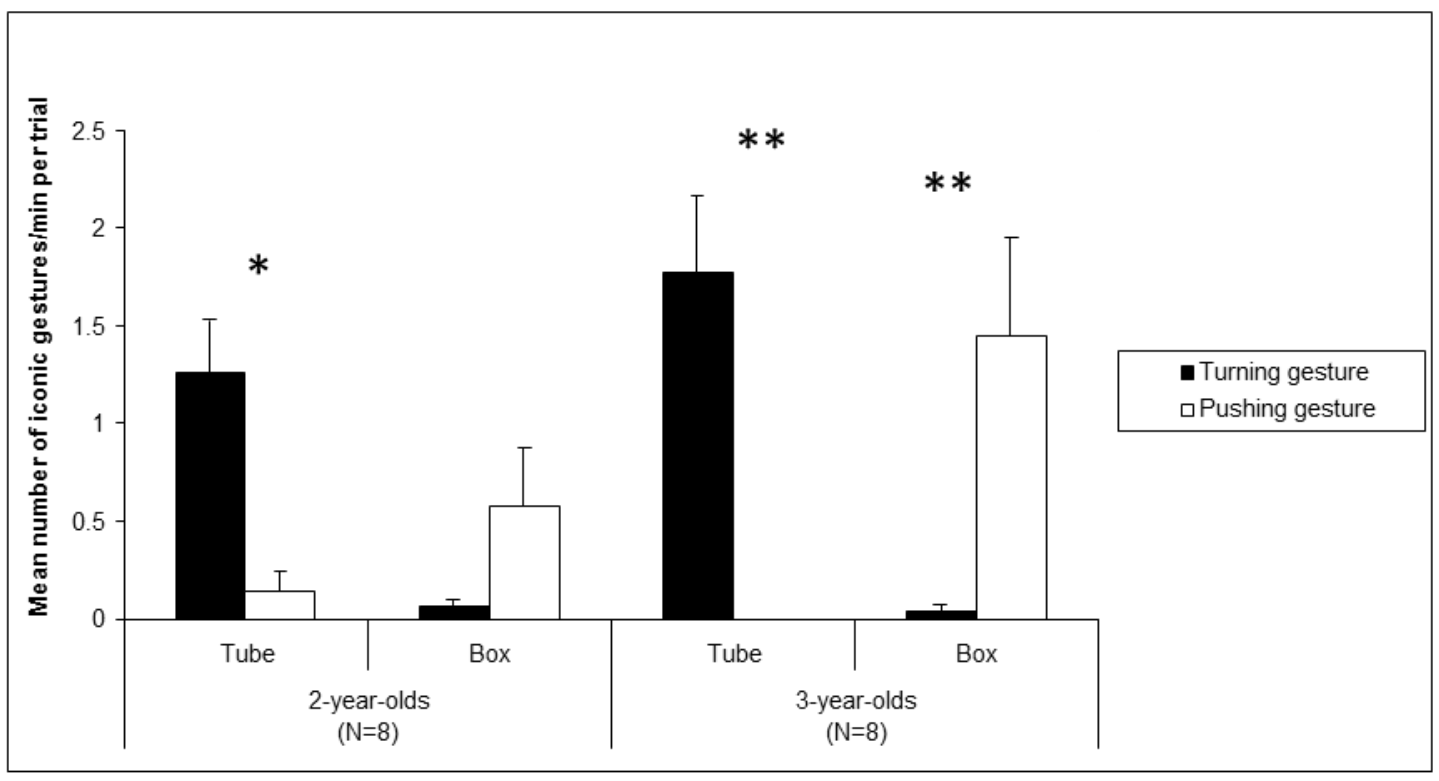


Figure 3. Mean number of pointing gestures per minute (and trial) as a function of condition, apparatus type, and age group for children. Asterisk indicates a significant difference between conditions $(* p<0.05)$.

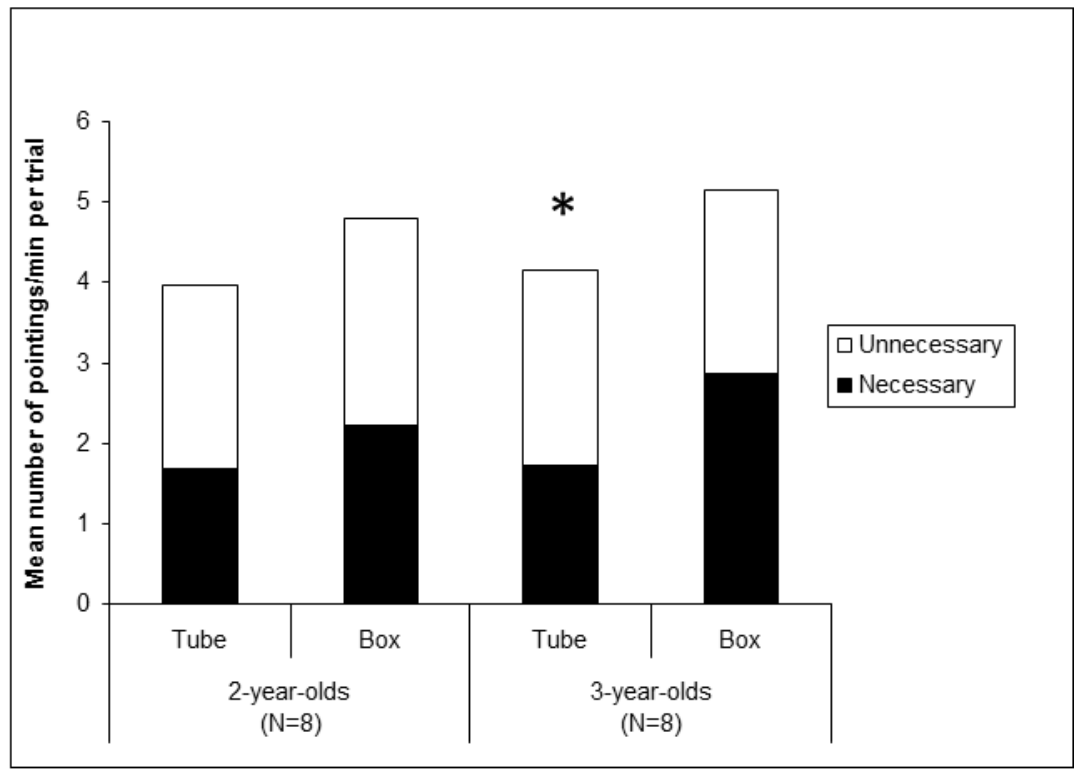


Figure 4. Mean (SEM) number of turning and pushing apparatus manipulations per minute (and trial) as a function of apparatus type and age group in the a) necessary and b) unnecessary conditions for children.

a)

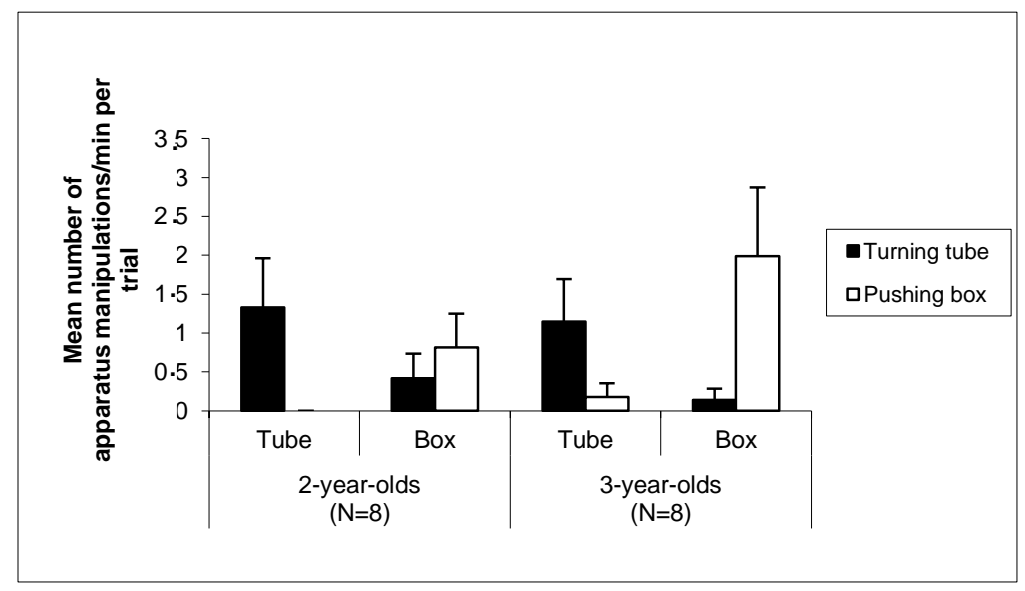

b)

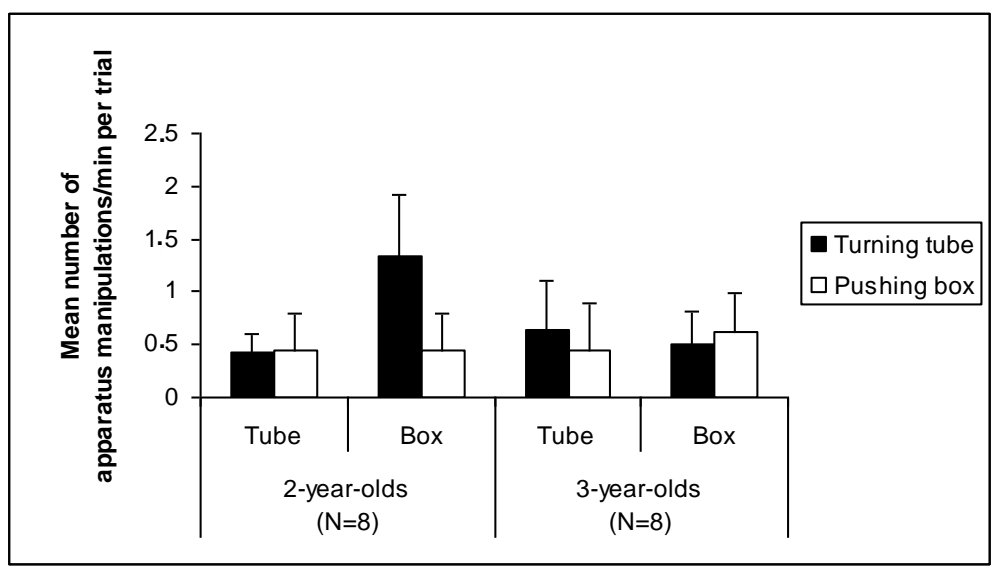


Iconic gestures 39

Figure 5. Mean number of pointing gestures per minute (and trial) as a function of condition, apparatus type, and species for apes.

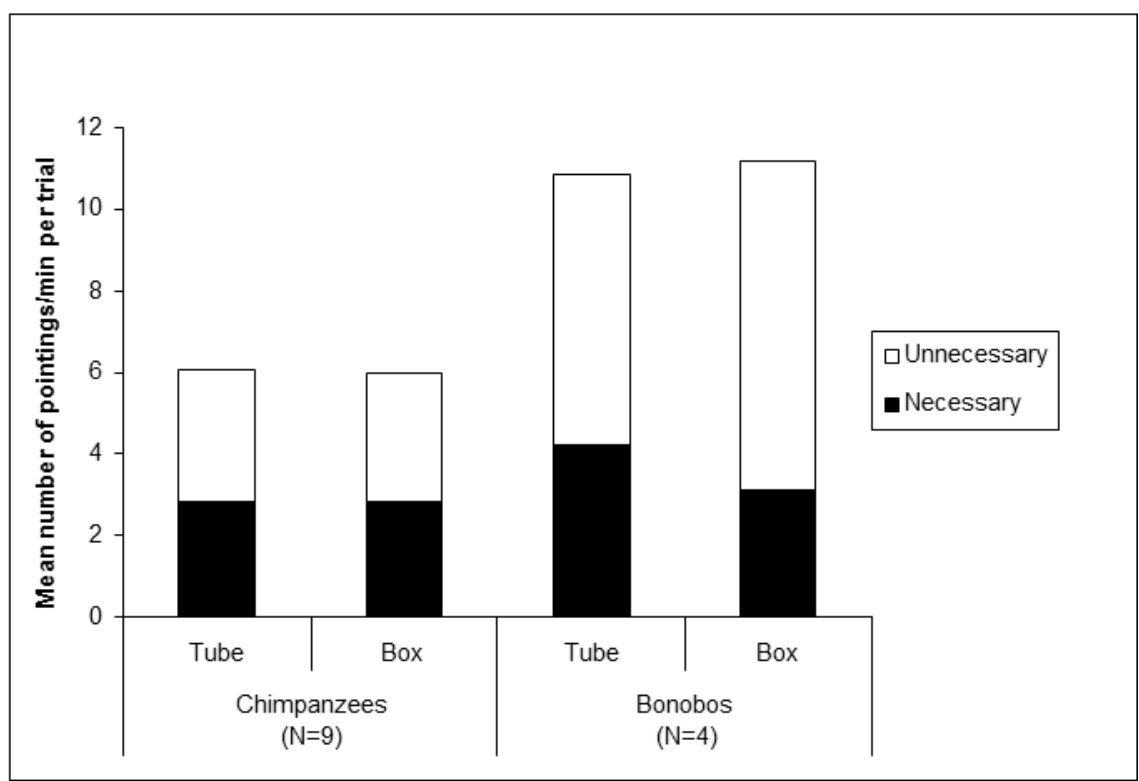


Figure 6. Mean (SEM) number of turning and pushing apparatus manipulations per minute (and trial) as a function of apparatus type and species in the necessary (a) and unnecessary (b) conditions for apes. Asterisk indicates a significant difference between conditions $(* p<0.05)$.

a)

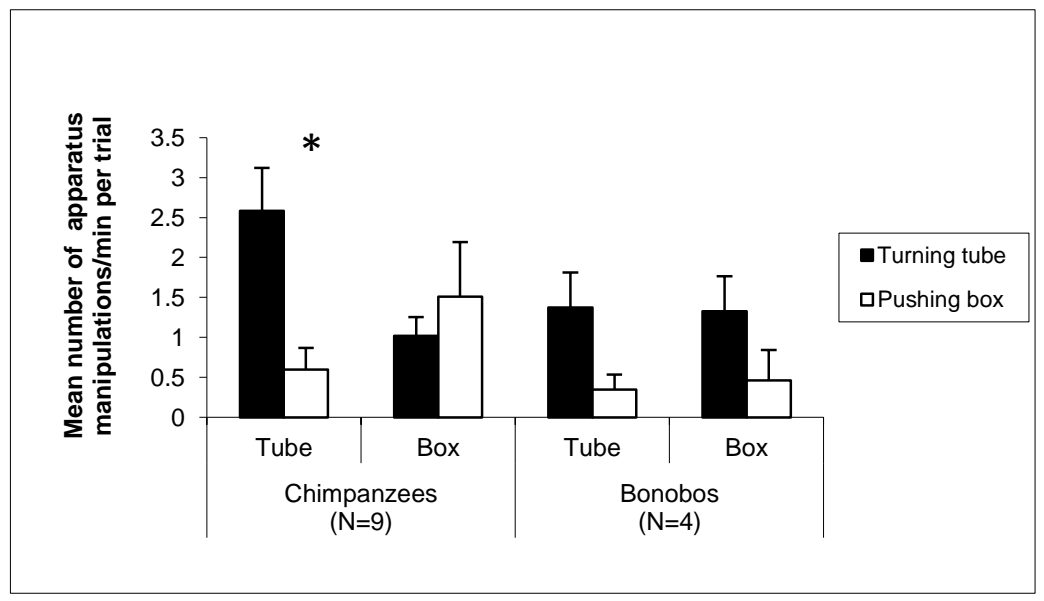

b)

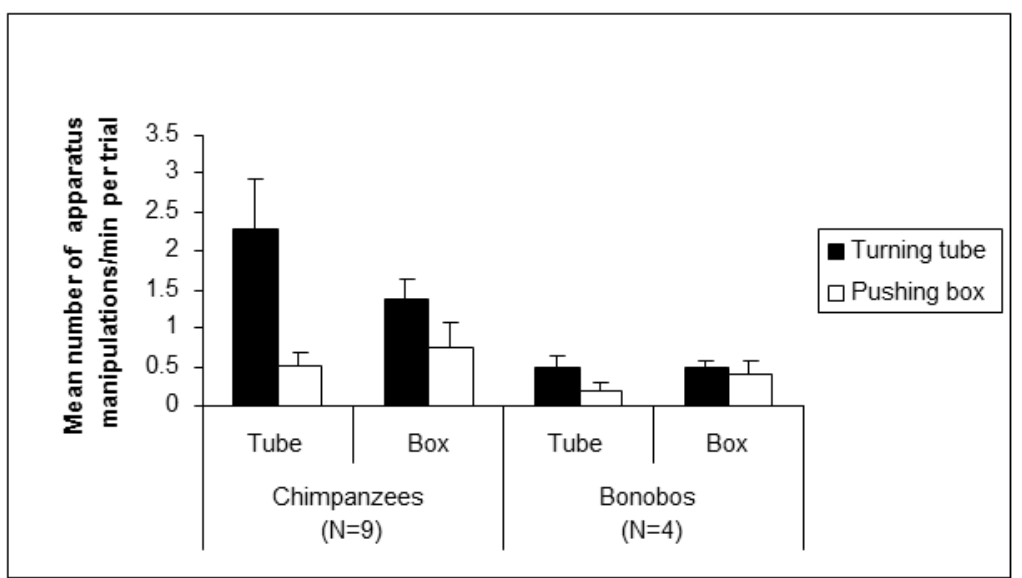

